\title{
On the Development of New Test Techniques to Measure the Tensile Response of Materials at High and Ultra-high Strain Rates
}

\author{
Junyi Zhou ${ }^{1} \cdot$ Vito L. Tagarielli ${ }^{2}$ (i)
}

Received: 9 April 2021 / Accepted: 16 August 2021 / Published online: 16 September 2021

(c) The Author(s) 2021

\begin{abstract}
Background There is a lack of reliable methods to obtain valid measurements of the tensile response of high performance materials such as fibre composites, ceramics and textile products at high rates of strain.

Objective We propose and assess two new test techniques aimed at measuring valid tensile stress versus strain curves at high and ultra-high strain rates.

Methods We conduct detailed, non-linear explicit Finite Element (FE) simulations of the transient response of the test apparatus and specimen during the tests and we develop simple analytical models to interpret the test measurements. We consider two test techniques: one based on the split Hopkinson bar apparatus, and suitable for strain rates of up to 1000 /s, and a second technique relying on projectile impact and aimed at measurements at strain rates higher than $1000 / \mathrm{s}$.

Results The simulations are successfully validated using test data at strain rates of order $200 / \mathrm{s}$ and then used to predict the test performance at strain rates up to approximately $5500 / \mathrm{s}$. We find that both techniques can give valid stress versus strain curves across a wide range of strain rates.

Conclusions We identify the limits of both techniques and recommend optimal measurement strategies for dynamic testing of materials with different ductility.
\end{abstract}

Keywords Tensile testing $\cdot$ Ultra-high strain rate $\cdot$ Ballistic impact $\cdot$ Ceramics $\cdot$ Composites $\cdot$ Fibres

\section{Introduction}

Measurements of the response of engineering materials at high rates of strain are of fundamental importance in many applications in the transportation and defence industry, as well as for the safety of civilians and in industrial operations. In these applications, high performance materials such as ceramics and composites outperform other types of engineering solids. On the other hand, the literature is practically lacking tensile data for these solids at high (100-1000/s) and ultra-high ( $>1000 / \mathrm{s})$ strain rates, due to test difficulties [1].

Tests at high rates of strain have been mostly performed using the well-established Hopkinson bar setup, which since

Vito L. Tagarielli

v.tagarielli@imperial.ac.uk

1 Department of Engineering Science, University of Oxford, Oxford OX1 3PJ, UK

2 Department of Aeronautics, Imperial College London, London SW72AZ, UK the pioneering studies of John and Bertrand Hopkinson and Kolsky [2-5] evolved to the modern split Hopkinson pressure bar (SHPB) proposed by Davies et al. [6]. This experiment, and its modifications to achieve tensile and torsional loading, have proved effective at high strain rates for most ductile materials. The method has an inherent problem in the fact that it yields valid results only after axial force equilibrium is achieved [7, 8]; as this typically happens beyond the elastic region of the material response, classical Hopkinson bar techniques cannot measure the dynamic elastic response and struggle when testing brittle materials, with difficulties increasing as the applied strain rate increases. Such brittle materials are also sensitive to mechanical gripping, resulting in measurements of strength lower than the actual material strength.

For the case of tensile testing at high or ultra-high strain rates, several authors have explored alternatives to the Hopkinson bar technique, and many of these tests were based on inducing circumferential stress on ring-shaped specimens, using explosives or ballistic impact [9-11] or electromagnetic forces [12-15] as a mean to generating suitable loading 
pulses. All these tests were demonstrated on ductile materials (metals in most cases) and all of them were not suitable to measure stress versus strain curves, which are in high demand by the materials modelling community.

We have recently developed a new test technique for tensile testing of engineering solids at high strain rate [16], in which the test principle was the dynamic internal pressurisation of ring-shaped specimens, and we have shown [16-18] that this is suitable for high strain rate testing of brittle and strong materials, demonstrating this up to a strain rate of $323 / \mathrm{s}$ and for a wide range of temperatures. This technique was shown to have several advantages over existing methods: the achievement of early force equilibrium, the elimination of gripping problems, the use of identical specimens in any test condition, and the suitability for studies of the effects of size, temperature and humidity on the measured response. The technique is suitable for testing monolithic rings, composite rings, fibre bundles or yarns, and materials in the form of tape. Unlike any other existing technique, the method in [16] was shown to be able to capture part of the elastic material response at high strain rate.

The objective of the present study is to pave the way to extending the strain rate range of such test technique. We will analyse two test setups based on the test principle above, studying the transient response of the test rig and specimen, and exploring different ways of generating the load and of taking the measurements, such to offer guidance to produce measurements of the tensile response of high-performance materials at rates never achieved before. In particular, we will develop four simple analytical models to guide the interpretation of the data measured in the proposed techniques, and assess their effectiveness in different cases by comparison to detailed Finite Element simulations.

In Sect. 2 we briefly describe the two test techniques and in Sect. 3 we present simple analytical models to guide the analysis of the test data. The FE simulations are described in Sect. 4 and results are presented and discussed in Sect. 5.

\section{Test Techniques}

In this section we describe the test techniques that we will assess vie FE simulations. Two different techniques will be analysed in this study. The first technique is the one presented in [16] and will be referred to as Test I. The second technique, which we will refer to as Test II, is an extension of Test I aimed at achieving ultra-high strain rates (which we define as rates higher than $1000 / \mathrm{s}$ ). Drawings of the test rigs used for Test I and a sketch of their use in conjunction with a SHPB are shown in Fig. 1.

Two versions of the test apparatus were presented in [16], both shown in Fig. 1a. These two versions are based on the same working principles and differ only in size and in the geometry of the loading pistons used. Four metallic cylinders and two steel plates are assembled to form a frame which supports and constrains two piston/cylinder assemblies; the assemblies sandwich a bespoke rubber sleeve, on which the specimen is mounted. The closed chamber created by the inner surface of the rubber sleeve, the cylinders and the pistons is filled with an incompressible fluid (water will be considered in this study).

The two pistons are then placed in contact with the input and output bars of a compression Hopkinson bar (SHPB), as sketched in Fig. 1b. This figure only shows the active part of the apparatus, and the rubber sleeve is idealised (and it will be modelled) as a thick-walled hollow circular cylinder (we refer the readers to [16] for drawings of the detailed geometry of such rubber sleeve). The SHPB is operated in the standard way: a compressive shockwave is generated following projectile impact and propagates down the input bar and piston, pressurizing the fluid and inducing hoop tension in the rubber sleeve and specimen. Both bars of the SHPB are instrumented with strain gauges to read transient strain histories and reconstruct, using one-dimensional stress wave theory, the stress history in the bars and the forces at their ends. Optionally, a pulse shaper can be inserted between impacting projectile and input bar, to adjust the magnitude and shape of the loading stress wave. In this study the pulse shapers will be rubber disks of fixed diameter and different thicknesses, as described below.

The maximum projectile impact speed that can be achieved in a SHPB apparatus is typically limited to approximately $20 \mathrm{~m} / \mathrm{s}$ by practical reasons. To allow higher impact velocities, generating higher strain rates in the specimens, we introduce Test II. The test apparatus and working principle of Test II are sketched in Fig. 2. The working principle of Test II is identical to that of Test I, with some key differences. Now the loading is induced, rather than by a SHPB, by impact of a high-speed projectile of small mass. The high stresses generated upon impact of the projectile with the loading piston may initiate plasticity in these components, which makes them disposable above a critical impact speed. The cylinder, on the other hand, is designed not to yield upon loading. A pulse shaper, as for Test I, can discretionally be placed at the interface between projectile and input piston. Only one cylinder/piston pair is present in Test II, and the pressurised chamber is formed by the cylinder/piston, the inner surface of the rubber sleeve, and a rigid metallic base. This base, and optionally the face of the input piston in contact with the fluid, may carry a piezoelectric transducer to measure the pressure history at those locations. The specimen is placed in contact with the external surface of the rubber sleeve and instrumented with circumferential strain gauges to measure the applied strain history. In the following we will consider the scenario where thin piezoelectric film pressure sensors (not shown in Fig. 2) are applied at the interface between the rubber sleeve and the specimen. The 
(a)

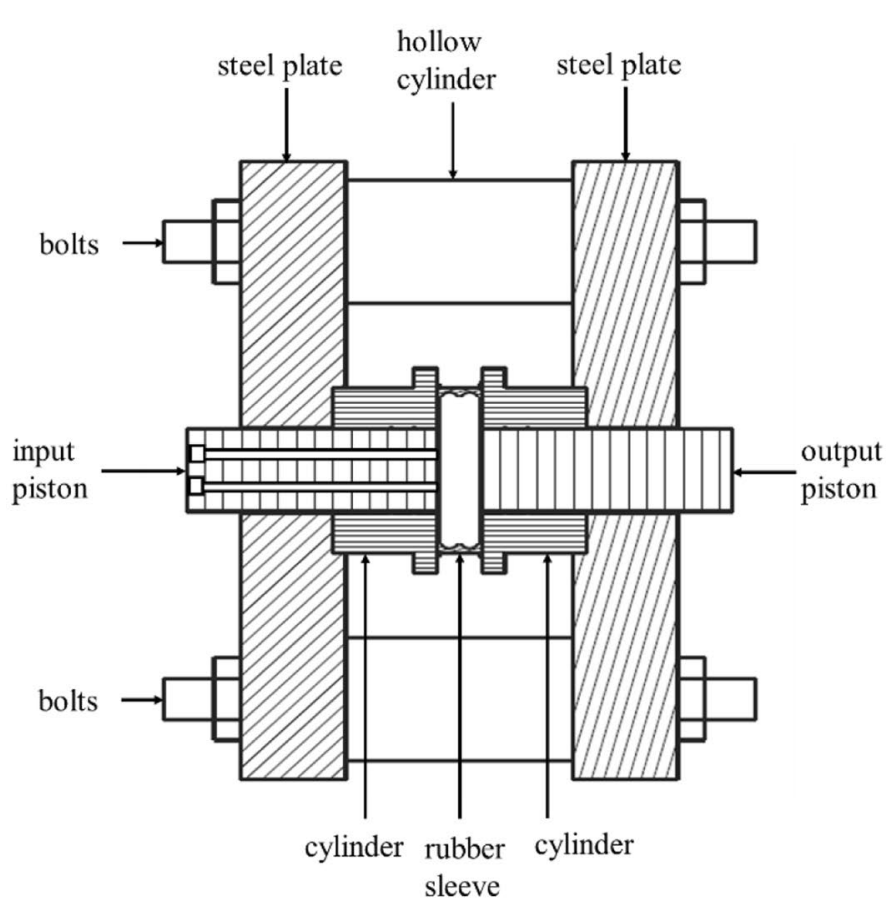

Version 2

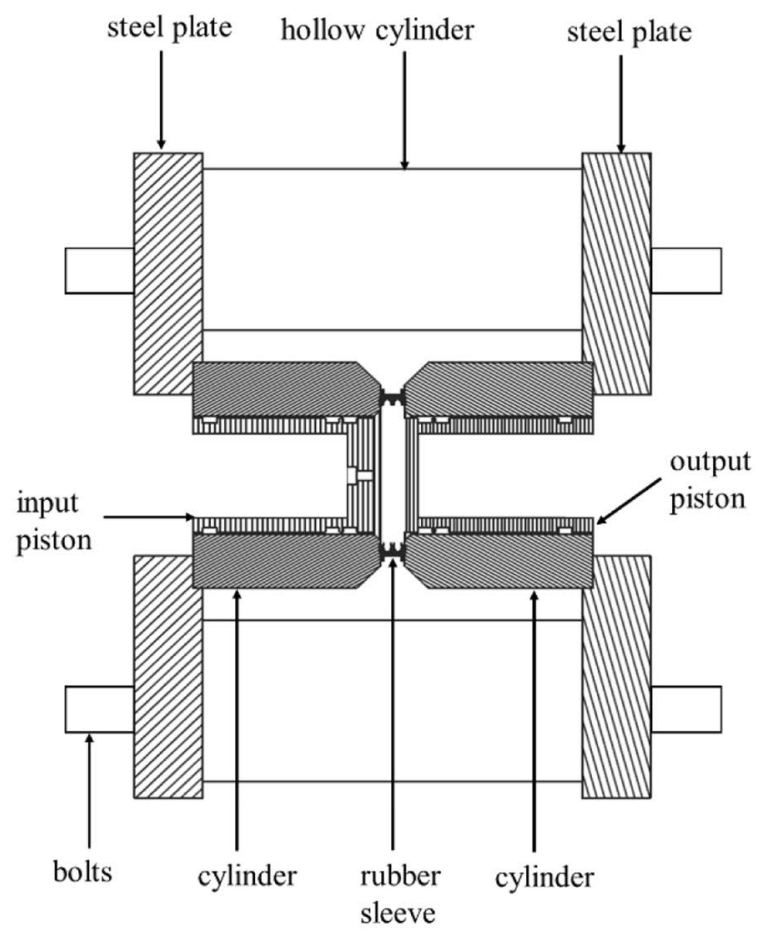

specimen rubber sleeve $(\phi 50, \mathrm{t}=0.1) \quad(\phi 50, \mathrm{t}=1)$

(b)

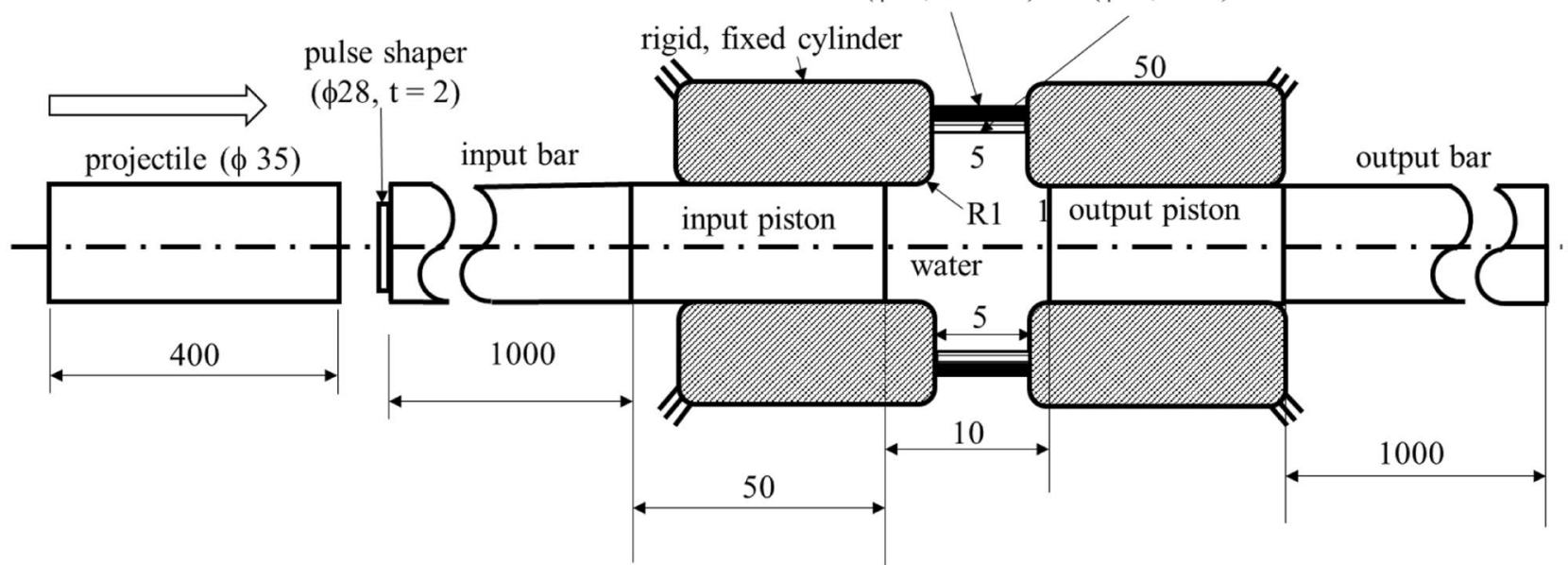

Fig. 1 Schematics of (a) the apparatus used for Test I and (b) the loading of the active part of the apparatus in a SHPB setup, as idealised in the FE simulations (not to scale; all dimensions in $\mathrm{mm}$ )

dimensions of the apparatus, also shown in Fig. 2, are the result of an optimisation of the design.

\section{Models for Data Analysis}

The working principles of tests I and II are identical. In this section we develop very simple analytical models aimed at determining the circumferential stress in the specimen as a function of the measurements of forces in the input and output bar (for Test I) or of the pressure measurements in the fluid and at the sleeve/specimen interface (for Test II).

Upon impact and the consequent motion of the input piston, stress waves are generated in the pressurized chamber; these move at sonic speed and are rapidly reflected multiple times at the chamber's walls. Neglecting such 


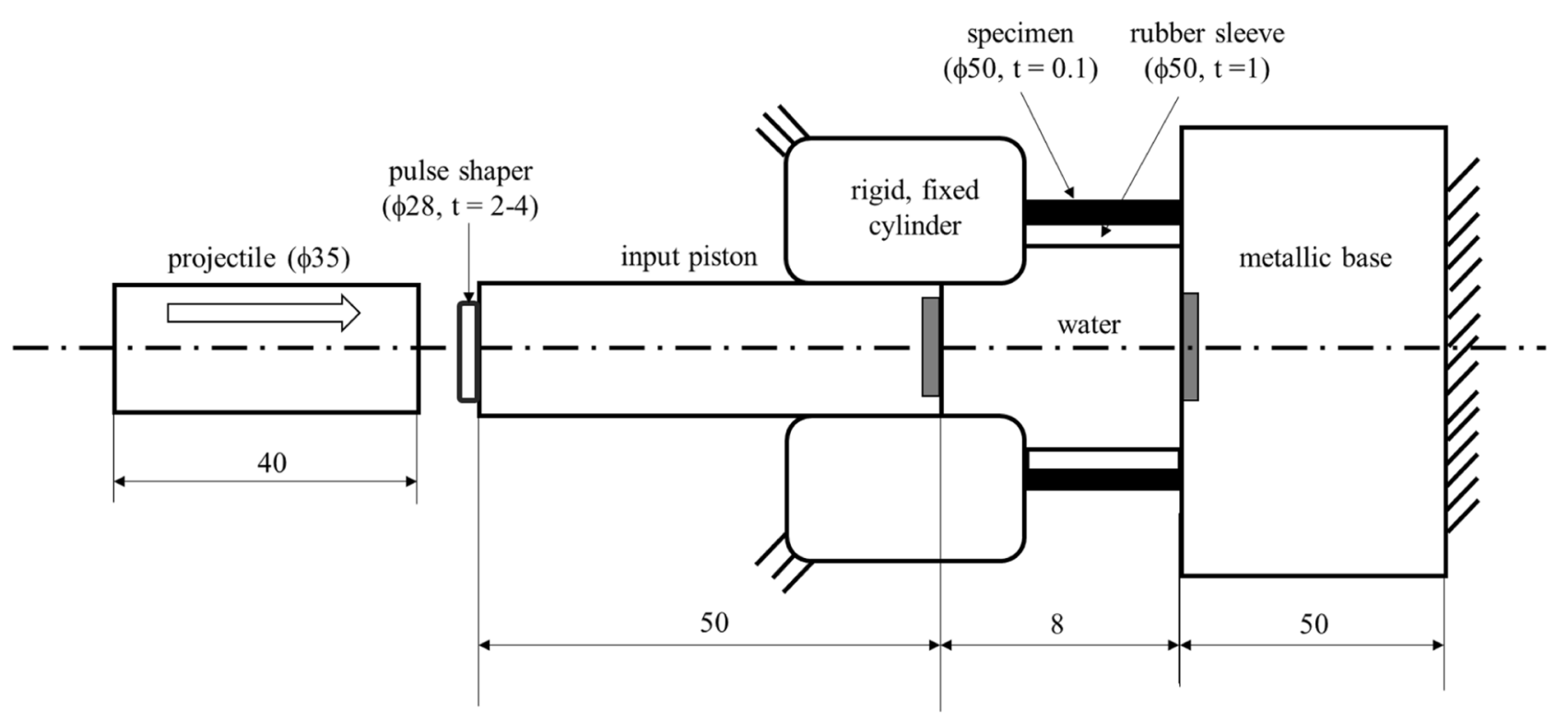

Fig. 2 Sketch of the experimental setup for Test II

initial transient and fluid-structure interaction effects, the loading results in a pressure history $p_{0}$ acting on the inner face of the rubber sleeve, as illustrated schematically in Fig. 3. In a quasi-static scenario $p_{0}=F / A_{0}$, where $A_{0}$ is the area of piston and $F$ is the force applied by the input piston to the fluid. The application of $p_{0}$ results in the rubber sleeve and specimen experiencing (average) circumferential stresses $\sigma_{R}$ and $\sigma_{S}$, respectively, and developing at their interface a pressure $p_{i}$ which can be read by film pressure transducers, if these are present.

The rubber sleeve is initially in contact with metallic surfaces for both tests I and II. Prior to the test, a slight compression is applied in the axial direction to facilitate sealing, resulting in the rubber sleeve carrying an axial pressure $p_{\text {axial }}$; during the test the rubber sleeve will also experience radial and circumferential strains, such that $p_{\text {axial }}$ can vary with time. As the rubber sleeve will slide in the radial direction relative to the metallic surfaces it is in contact with, this will result in a radial distribution of frictional shear forces of magnitude indicated by $f\left(p_{\text {axial }}\right)$. Considering the sleeve and specimen as thin-walled cylinders with common position $r$ (the position of their interface), their radial acceleration will result in inertial forces per unit length $\rho_{R} A_{R} \ddot{r}$ for the rubber sleeve and $\rho_{S} A_{S} \ddot{r}$ for the specimen, where $\rho$ indicates the mass density, $A$ denotes a cross-sectional area, and subscripts $R$ and $S$ refer

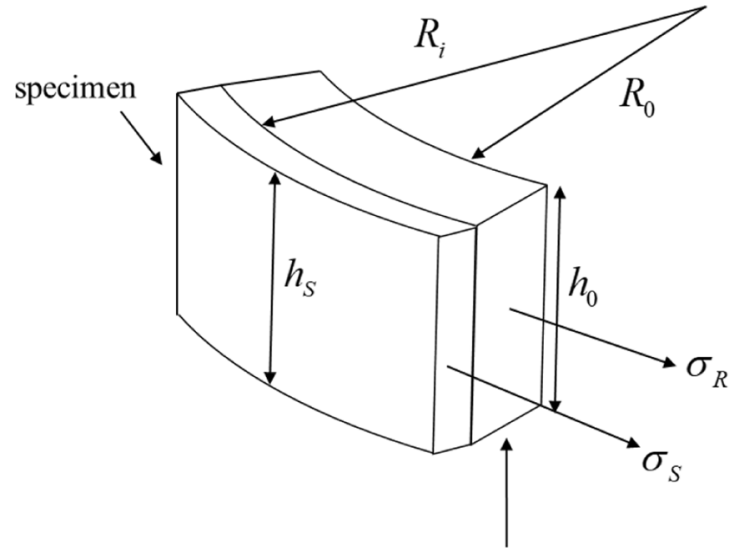

rubber sleeve

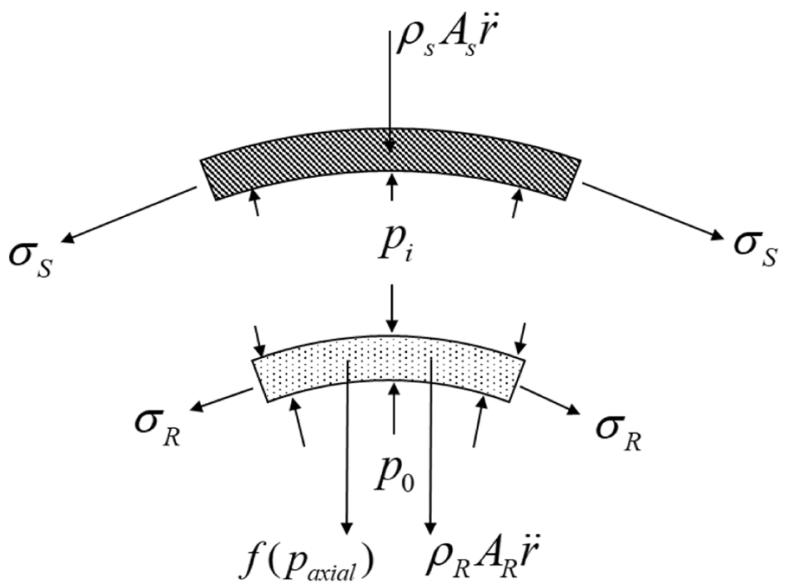

Fig. 3 Three-dimensional (left) and planar (right) view of the active part of the apparatus, its geometry, and the forces involved 
to the rubber sleeve and specimen, respectively, and the double dot denotes the second derivative with respect to time. The fluid in the pressurised chamber also accelerates radially, however due to its small volume and density, in the following we neglect the existence of inertia forces associated with the fluid.

We now write down four different equations relating the circumferential stress in the specimen to the other parameters, based on different sets of assumptions. In the following we will assume that the specimen is a monolithic ring with rectangular cross-section, however this assumption can be easily relaxed when focusing on testing of fibre bundles, as described in [16-18].

Model 1. Rubber sleeve and specimen are treated as thinwalled cylinders; frictional and inertia forces are neglected. Equilibrium of the specimen and rubber sleeve reads

$\sigma_{S} A_{S}=p_{i} R_{i} h_{S} \sigma_{R} A_{R}+p_{i} R_{i} h_{S}=p_{0} R_{0} h_{0}$

where $h_{0}, h_{S}$ are the axial dimensions of rubber sleeve and specimen, respectively, $R_{0}$ is the initial position of the inner surface of the rubber sleeve (we will assume that this does not change during the test) and $R_{i}$ is the initial position of the sleeve/specimen interface. If the constitutive response of the rubber sleeve material subject to uniaxial stress in the hoop direction is known, as $\sigma_{R}=\sigma_{R}(\varepsilon)$, equation (1) can be re-written as

$\sigma_{S}=\frac{1}{A_{S}}\left[R_{0} h_{0} p_{0}-A_{R} \sigma_{R}(\varepsilon)\right]$

Measuring the pressure history in the fluid, and knowing the constitutive response of the rubber sleeve, allow determining the history of circumferential stress in the specimen; this was demonstrated in [16-18], where it was also shown that the term $A_{R} \sigma_{R}(\varepsilon)$ in equation (2) can be safely neglected when testing materials that are sufficiently stiff and strong.

Model 2. Here we make the same assumptions of Model 1 but we include frictional effects arising from the sliding of the rubber sleeve against the metallic surface of the cylinder. The frictional shear stresses at the top and bottom surfaces of the rubber sleeve are proportional to the coefficient of dynamic friction $\mu \approx 0.25$ (between rubber and smooth, well-lubricated, flat metallic surfaces [19]) and to the axial pressure $p_{\text {axial }}$ This pressure is the sum of the initial pressure $p_{\text {initial }}$ applied prior to the test (in the assembly phase) and the axial stress induced during the test $\sigma_{a}$, i.e. $f\left(p_{\text {axial }}\right)=\mu\left(p_{\text {initial }}+\sigma_{a}\right.$. Assuming (in first approximation) that the magnitude of shear frictional forces is uniform on the (approximately constant) contact area, this gives
$\sigma_{S}=\frac{1}{A_{S}}\left[\frac{R_{0} h_{R} F}{A_{0}}-A_{R} \sigma_{R}(\varepsilon)-\mu\left(R_{i}^{2}-R_{0}^{2}\right)\left(p_{\text {initial }}+\sigma_{a}\right)\right]$

Modelling the rubber sleeve as an incompressible, thickwalled cylinder subject to internal pressure $p_{0}$, external pressure $p_{i}$ and negligible axial strain, the axial stress $\sigma_{a}$ can be calculated using using Lamé Equations as

$\sigma_{a}=\frac{p_{0} R_{0}^{2}-p_{i} R_{i}^{2}}{R_{i}^{2}-R_{0}^{2}}$

Rearranging, we obtain

$$
\begin{aligned}
\sigma_{S} & =\frac{1}{A_{S}}\left[\left(\frac{h_{0}-\mu R_{0}}{h_{S}-\mu R_{i}}\right) R_{0} h_{S} p_{0}-\frac{h_{S}}{h_{S}-\mu R_{i}} A_{R} \sigma_{R}(\varepsilon)\right. \\
& \left.-\frac{\mu\left(R_{i}^{2}-R_{0}^{2}\right) h_{S}}{h_{S}-\mu R_{i}} p_{\text {initial }}\right]
\end{aligned}
$$

which allows calculating the stress in the specimen from measurements of the internal pressure $p_{0}$, and the initial axial pressure $p_{\text {initial }}$ The latter can be easily measured in preliminary tests, however we noted that the term containing $p_{\text {initial }}$ in equation (5) is negligible, compared to the other two terms, in most practical cases. We also note that the axial stress $\sigma_{a}$ can in principle be negative (depending on the relative magnitude of $p_{0}$ and $p_{i}$ ) such to cause loss of contact from the metallic surfaces (as well as causing failure of the test for loss of pressurization and invalidating equation (5)); this is however unlikely in most practical cases, and the risk of loss of contact can be mitigated by increasing $p_{\text {initial }}$.

Model 3. This model is identical to Model 2 but also accounts for the inertia forces acting on the specimen and rubber sleeve. This results in the expression

$$
\begin{aligned}
\sigma_{S} & =\frac{h_{0}-\mu R_{0}}{h_{S}-\mu R_{i}} \frac{R_{0} h_{S} p_{0}}{A_{S}}-\frac{h_{S} A_{R} \sigma_{R}(\varepsilon)}{A_{S}\left(h_{S}-\mu R_{i}\right)}-\frac{\mu\left(R_{i}^{2}-R_{0}^{2}\right) h_{S}}{\left(h_{S}-\mu R_{i}\right) A_{S}} p_{\text {initial }} \\
& -\frac{h_{S}}{h_{S}-\mu R_{i}}\left(\rho_{R} \frac{A_{R}}{A_{S}} R_{0}^{2}+\rho_{S} R_{i}^{2}\right) \ddot{\varepsilon}_{\theta}
\end{aligned}
$$

in which $\ddot{\varepsilon}_{\theta}$ is the second derivative in time of the hoop strain, which can be measured by a strain gauge adhered on the test specimen with appropriate high-speed data acquisition.

Model 4. If thin film pressure sensors are used at the interface between the rubber sleeve and the specimen, allowing a direct measure of the interface pressure $p_{i}$, the circumferential stress in the specimen is simply

$\sigma_{S}=\frac{p_{i} R_{i} h_{S}}{A_{S}}-\rho_{S} R_{i}^{2} \ddot{\varepsilon}_{\theta}$ 
where the second term is related to the inertia of the specimen and was found negligible for the specimen modelled in this study, even at the highest strain rate considered.

Models 1-4 can be used to interpret the measurements made using both Test I and Test II, depending on the instrumentation of the tests. From the discussion above, direct measurements of the interface pressure and use of Model 4 is in a way the simplest route, as it does not require knowledge of the response of the rubber sleeve and is independent on the transient propagation of pressure waves in the fluid, as well as friction and inertia of the rubber sleeve and fluid. The sleeve in this case can be manufactured out of any easily machinable material with conventional methods; on the other hand, the measurement of the interface pressure may be difficult to realise in practice, as it involves placing a sensor on moving and deformable parts.

If such direct measurement cannot be pursued, to determine the stress in the specimen one needs to measure the fluid pressure $p_{0}$. In Test I this can be made by measuring the forces at the ends of the input and output bars, while in Test II it can be achieved by one or multiple pressure sensors in the pressurised chamber, as it is difficult to place such sensors directly at the surface of the deformable supporting sleeve. For both techniques it is therefore necessary to ensure that the pressure is approximately uniform in the chamber; in particular, for Test I this would mean that the forces in the input and output bars (having equal cross-sectional area) need to equalise, i.e. the SHPB system needs to achieve force equilibrium; however, force equilibrium is a necessary, but not sufficient condition to ensure uniformity of the fluid pressure in the chamber. For these reasons it is important to analyse the details of the transient loading of the test rigs and the fluid for both Test I and Test II, which will be done via FE simulations described in the following section. These FE analyses will also serve as a benchmark to assess the effectiveness of the above models.

\section{Finite Element Simulations}

Detailed explicit FE simulations of tests I and II were performed with the commercial FE software Abaqus Explicit (SIMULIA ${ }^{\mathrm{TM}}$ Abaqus 6.14, Dassault Systèmes). The geometries of the models used for tests I and II are in accordance with the sketches and the dimensions in Figs. 1 and 2 . The active parts of the test rigs have axial symmetry, consequently all parts were meshed by $2 \mathrm{D}$ axisymmetric finite elements.

In simulations of Test I the projectile, input bar and pistons were assigned isotropic elastic-plastic properties corresponding to those of a titanium alloy (Ti64 or Ti6AL-4 V), taken from the literature and specified in Table 1; $\mathrm{J} 2$ incompressible plasticity with isotropic hardening was chosen to represent the yielding of this metallic alloy. The cylinders were modelled as rigid, fixed parts, as their deformation can be made negligible by appropriate design. The output bar of the SHPB was assigned a linear elastic isotropic response representative of PMMA; the choice of this polymeric material is quite common in SHPB applications with specimens of relatively low stiffness and strength (as it is the case for the water-sleeve-specimen assembly here), and is driven by the need of maximising the strain-to-noise ratio [20, 21].

In simulations of Test II, the impactor, input piston and metallic base were assigned the properties of a Ti64 alloy taken from [22]. The cylinder was again treated as a rigid body.

For both tests, the rubber sleeve and the optional pulse shapers were modelled as isotropic, neo-Hookean hyperelastic materials, with properties as measured in our previous studies [16]. We note that in these studies we measured the response of the rubber up to a strain rate of $400 / \mathrm{s}$, but the simulations presented here will involve strain rates much higher than this; pragmatically, here we use the properties measured in [16] for impact speeds up to $20 \mathrm{~m} / \mathrm{s}$ (Test I), while we double the initial stiffness of the rubber for tests at impact speeds above $20 \mathrm{~m} / \mathrm{s}$ (Test II), in a first-order attempt at capturing the strain rate sensitive response of this material.

The response of water was modelled by a Mie-Grüneisen equation of state, with a linear Hugoniot relation between applied pressure and volumetric strain; a tension cut-off was also modelled at pressure equal to the absolute zero, to model the effects of cavitation; a dynamic viscosity was also included. This modelling approach has been validated successfully in several studies on underwater explosions (for example [23-25]).

It was assumed in all cases that the test specimen was a composite fibre yarn wound around the rubber sleeve in the circumferential direction, representative of the Dyneema yarn tested in [16] at strain rates up to 209 /s. This displayed an approximately linear response with stiffness of $150 \mathrm{GPa}$ at this strain rate; being a fibre yarn, it possessed stiffness only in the axial direction. This textile material therefore had negligible Poisson's ratio, transverse and shear stiffness and was modelled as a linear elastic anisotropic solid using the option 'elastic lamina constants' in Abaqus, assigning to it only axial stiffness and negligibly small transverse and shear stiffnesses of $1 \mathrm{kPa}$. The materials to test with the proposed technique are expected to be rate-sensitive, as we have demonstrated in [16-18] for high-performance fibres. We note that the inevitable (and relatively small) variations of the applied 
strain rate during a single test are not expected to make a significant contribution to the functionality of the apparatus: from the data in [16-18] one can deduce for example that the variations in stiffness of the materials we previously tested never exceed $10 \%$ in a single test. Consequently, a rate-insensitive model is chosen, for simplicity, to model the specimen. From the application of the time-temperature superposition principle presented in [18] we can estimate the stiffness of the material modelled in this study as $200 \mathrm{GPa}$ at a strain rate of $10^{5} / \mathrm{s}$, while this stiffness is of $150 \mathrm{GPa}$ at strain rates of order $100 / \mathrm{s}$. To capture the material's different response in the two types of tests in first approximation, similarly to what done for the rubber sleeve material, we use a stiffness of $150 \mathrm{GPa}$ for impact speeds up to $20 \mathrm{~m} / \mathrm{s}$ (Test I) and of $200 \mathrm{GPa}$ for tests at impact speeds above $20 \mathrm{~m} / \mathrm{s}$ (Test II). All relevant properties assigned to the different materials in the FE simulations are listed in Table 1.

The geometries of the two simulated test setups were determined by a trial and error optimisation process not discussed here for the sake of brevity. Dimensions are shown in Figs. 1 and 2. For both tests I and II, the specimens and rubber sleeve were similar to those used in Version 2 of the apparatus presented in [16], with specimen of height $5 \mathrm{~mm}$, thickness $0.1 \mathrm{~mm}$ and diameter $50 \mathrm{~mm}$. The rubber sleeve had wall thickness of $1 \mathrm{~mm}$ and height $5 \mathrm{~mm}$. Pistons had diameter $35 \mathrm{~mm}$ and length of $50 \mathrm{~mm}$. The pulse shapers had diameter of $28 \mathrm{~mm}$ and thickness varying from 1 to $4 \mathrm{~mm}$.

In Test I, the two pistons are positioned at an initial separation of $10 \mathrm{~mm}$ as shown in Fig. 1b; the profile of the two cylinders had corners rounded by a radius of $1 \mathrm{~mm}$, as this was found to mitigate water cavitation in the tests (and to facilitate modelling). The impacting projectile had length of $400 \mathrm{~mm}$ while the input and output bars were $1 \mathrm{~m}$ long, following a classical design for small SHPBs. In Test II, the initial separation of input piston and metallic base was of $8 \mathrm{~mm}$, and the projectile used has a length of $40 \mathrm{~mm}$.

Surface-to-surface contacts and tie constraints were used to define the interactions between pairs of surfaces. The rigid cylinder(s) were fully constrained and had frictionless contact with the piston(s). The pistons were initially in frictionless contact with the input bar (Test I) or projectile (Test II). The water domain was tied to the inner surface of the pressurised chamber, comprising appropriate portions of the piston(s), rigid cylinder(s), rubber sleeve and metallic surface (for Test II). The rubber sleeve was in frictional contact $(\mu=0.25)$ with the rigid cylinder(s) and in frictionless contact with the inner surface of the specimen.

A mesh convergence study determined that the simulation results were insensitive to the mesh size when the global mesh size was at least $0.2 \mathrm{~mm}$ for all parts. Such global element size was used in conjunction with the automatic meshing tool of Abaqus CAE, for all parts. The water domain was meshed by triangular free meshes, while the meshes of all other parts were quadrilateral-dominated. Therefore a combination of 3-noded linear axisymmetric triangle elements (CAX3) and 4-noded bilinear axisymmetric quadrilateral elements (CAX4R) were used in the simulations.

\section{Results and Discussion}

\section{Pressure Transient and Cavitation Effects}

As discussed in Sect. 2, ensuring that the pressure in the water achieves rapidly an approximately uniform distribution is a key requirement for both tests. It is also important to avoid substantial cavitation in the pressurised chamber, as this would lead to complex fluid-structure interaction phenomena [23-25] which are hard to predict and would make interpretation of the test results difficult.

Table 1 Summary of the materials and material properties used in the FE simulations

\begin{tabular}{|c|c|c|c|c|c|c|}
\hline Material & $\begin{array}{l}\text { Density } \\
\left(\mathrm{kg} / \mathrm{m}^{3}\right)\end{array}$ & Material response & $\begin{array}{l}\text { Elastic modulus } \\
\text { Test I | Test II }\end{array}$ & Poisson's ratio & Additional inputs & Relevant parts \\
\hline Ti-6AL-4 V [22] & 4500 & $\begin{array}{l}\text { isotropic } \\
\text { elasto-plastic }\end{array}$ & $110 \mathrm{GPa}$ & 0.27 & $\begin{array}{l}\text { perfectly plastic } \\
\sigma_{Y}=1 \mathrm{GPa}\end{array}$ & $\begin{array}{l}\text { Impactors; } \\
\text { Input bar/pistons; } \\
\text { Metallic base }\end{array}$ \\
\hline PMMA [22] & 1800 & Elastic-Isotropic & $4 \mathrm{GPa}$ & 0.33 & - & Output bar \\
\hline Rubber [16] & 800 & $\begin{array}{l}\text { Hyperelastic } \\
\text { Neo-Hookean }\end{array}$ & $1 \mid 2 \mathrm{GPa}$ & 0.495 & - & $\begin{array}{l}\text { Pulse shapers; } \\
\text { Rubber sleeve }\end{array}$ \\
\hline $\begin{array}{c}\text { composite fibre } \\
\text { yarn }[16,18]\end{array}$ & 970 & $\begin{array}{l}\text { Elastic-Engineering } \\
\text { constant }\end{array}$ & $\begin{array}{c}\mathrm{E}_{11}=150 \mid 200 \mathrm{GPa} \\
\mathrm{E}_{22}=\mathrm{E}_{33}=\mathrm{G}_{12}= \\
\mathrm{G}_{13}=\mathrm{G}_{23}=1 \mathrm{kPa}\end{array}$ & $10^{-6}$ & $\begin{array}{l}\text { Shear Modulus } \\
\mathrm{G} 12=\mathrm{G} 13=\mathrm{G} 23=1 \mathrm{kPa}\end{array}$ & Test specimen \\
\hline $\begin{array}{l}\text { Water } \\
\text { [23-25] }\end{array}$ & 1000 & Mie-Grüneisen EOS & $\begin{array}{l}\text { Bulk modulus } \\
2.2 \mathrm{GPa}\end{array}$ & - & $\begin{array}{l}\text { Wave speed } 1500 \mathrm{~m} / \mathrm{s} \\
\text { Viscosity } 8.910^{-4} \mathrm{Pas}\end{array}$ & Fluid \\
\hline
\end{tabular}


In a preliminary study of the role of the geometry of the pressurised chamber, we found that these two objectives are achieved by: (i) maximising the ratio between crosssectional area of the piston and wetted area of the rubber sleeve (which also maximises the strain rate for a given impact velocity); (ii) maximising the ratio between diameter and height of the rubber sleeve; and (iii) avoiding very sharp corners in the pressurised chamber. The optimal geometry simulated in this study is the result of the application of these three design principles.

In Fig. 4a we present contours of the fluid pressure at four selected times, for the case of Test I conducted at an impact speed of $8 \mathrm{~m} / \mathrm{s}$, using a pulse shaper of thickness $2 \mathrm{~mm}$. At $t=0$ a stress wave propagating in the input piston impinges on the piston/water interface; at $t=20$ $\mu \mathrm{s}$ the consequent propagation of this stress wave in the water results in a non-uniform pressure distribution; we note that the distance between the pistons was of $10 \mathrm{~mm}$ and stress waves in water travel at a speed of $1500 \mathrm{~m} / \mathrm{s}$, taking just under $7 \mu$ s to travel from the input to the output piston; therefore, at $t=20 \mu \mathrm{s}$ the stress wave has been already reflected 2 times and the system of rubber sleeve and specimen has been set in motion. At $t=60$ $\mu$ s the stress wave has reflected approximately 10 times at the solid interfaces, and the pressure in the chamber has become approximately uniform, while the sleeve and specimen continue to expand radially. At $t=150 \mu \mathrm{s}$ the pistons and specimen have displaced substantially; the consequent rarefaction wave emanating from the water/ sleeve interface results in localised cavitation occurring in the proximity of the corner of the chamber, at the point indicated by the arrow in Fig. 4d. These events involve the creation of an approximately toroidal cavitation front growing from this corner, and then collapsing onto itself after approximately $50 \mu \mathrm{s}$. This is visible in the pressure history shown in Fig. 4b, recorded at the location indicated by the arrow. Clearly this small cavitation event does not affect substantially the uniformity of the pressure field, and the pressure at the interfaces with the pistons, which can be measured by the strain gauges on the input and output bars of the SHPB, closely follows the pressure applied on the rubber sleeve.

Therefore the value of $p_{0}$ can be determined from readings of the stress in the input and output bars, after force equilibrium has been achieved (this has indeed happened by $t=60 \mu \mathrm{s})$. Similar analyses conducted at different impact speeds show that in the range of applicability of Test I (impact speed up to $20 \mathrm{~m} / \mathrm{s}$ ), cavitation never presents a serious problem for the test, and that a uniform pressure field is achieved within tens of microseconds from $t=0 \mu \mathrm{s}$, which corresponds to small strains in typical specimens. Consequently, Test $\mathrm{I}$ is suitable for determining valid stress versus strain curves for most solid materials (as we have already demonstrated experimentally in [16] for different materials possessing wide ranges of stiffness, strength and ductility), and with a careful design it can also capture part (a)

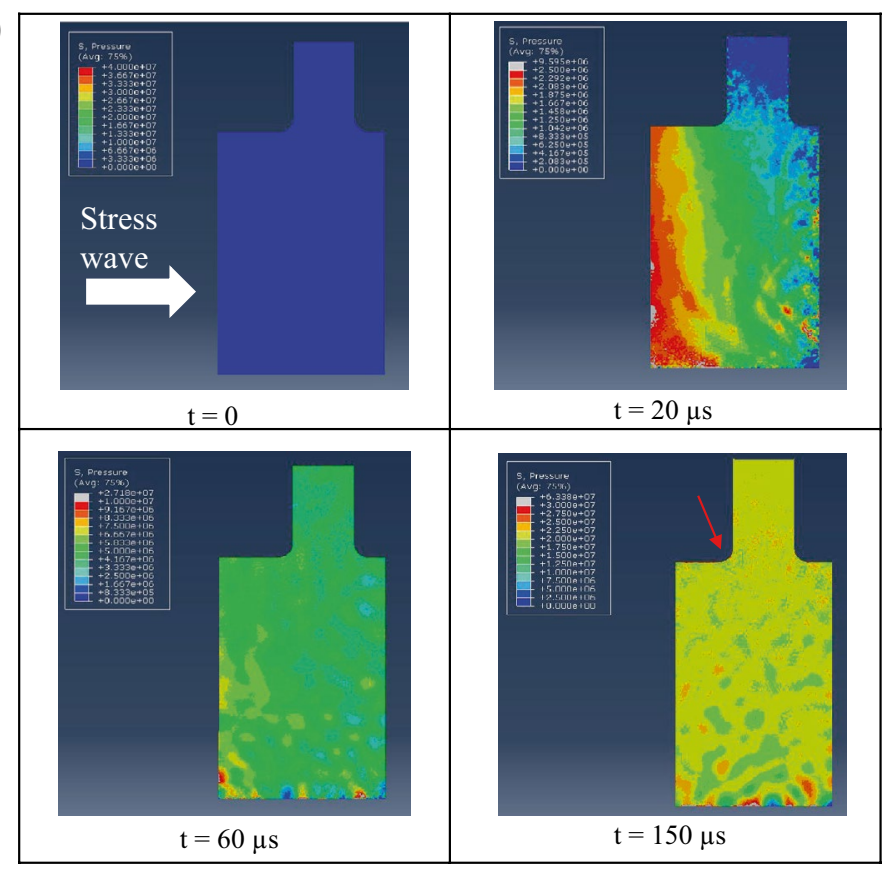

(b)

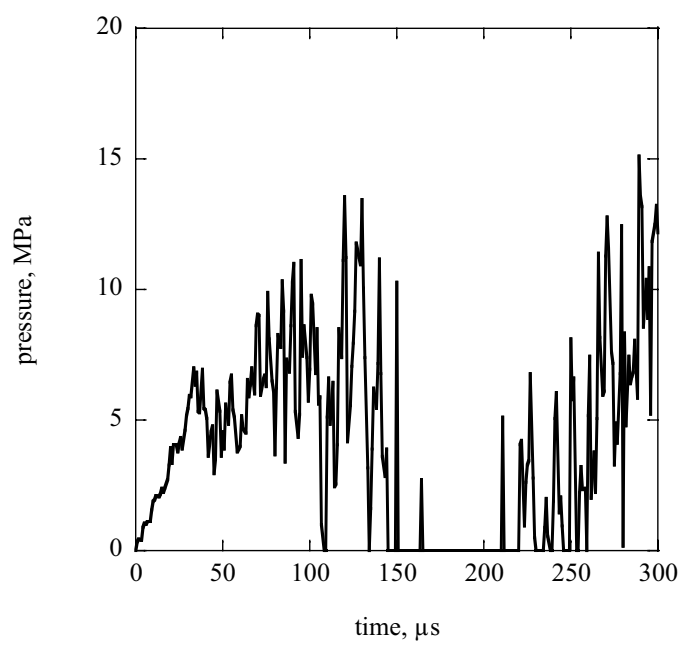

Fig. 4 (a) Predicted pressure field in the water at four selected times, for a Test I at impact speed of $8 \mathrm{~m} / \mathrm{s}$, with a pulse shaper of thickness $2 \mathrm{~mm}$; (b) Corresponding pressure history at the location indicated by the red arrow in part (a) 
of the elastic response of the materials tested. For the case of Test II, similar conclusions hold for projectile impact speeds up to approximately $100 \mathrm{~m} / \mathrm{s}$. For this test we found that measurements of the pressure at the input piston and at the metallic base (the two pressure gauges indicated in Fig. 2) yield the same results after a very brief transient, which leads to the conclusion that instrumenting the input piston with a pressure transducer is not necessary. When impact speeds approach $100 \mathrm{~m} / \mathrm{s}$ however, the readings of these two pressure gauges differ substantially from the interface pressure $p_{0}$.

\section{Relative Importance of Friction and Inertia}

Next, we investigate the accuracy of the analytical models in Sect. 3, to determine the relative importance of frictional and inertial forces on the measurements. Figure 5 presents the results of simulations at impact speeds of $8 \mathrm{~m} / \mathrm{s}$ (Test I, Fig. 5a) and $50 \mathrm{~m} / \mathrm{s}$ (Test II, Fig. 5b). For Test I, the history of $p_{0}$ is obtained from the stresses in the output bar, while for Test II the same history is obtained by measuring the pressure at the metallic base (an average pressure over a circular patch of diameter $35 \mathrm{~mm}$, to mimic what a pressure transducer would read). For both tests the circumferential strain history is extracted at the outer surface of the specimen, to mimic the presence of a hoop strain gauge, and the average interface pressure $p_{i}$ is also recorded. These readings are then used as inputs to Models 1 to 4 , and used to construct stress versus strain curves according to each of these models. These curves are plotted in Fig. 5 together with the constitutive response used in the FE simulations, which represents a benchmark to assess the effectiveness of the different models.

At the low impact speed of $8 \mathrm{~m} / \mathrm{s}$, models 1,2 and 3 yield practically identical results; this indicates that frictional and inertial effects play a very small role in this regime. Initially they all disagree with the reference stress/strain curve, due to the fact that force equilibrium has not yet been reached, but they follow the reference curve from a strain of approximately $1 \%$. Model 4 follows the reference curves immediately and much more closely, producing a stress/strain curve with very small noise. We recall that Model 4 is informed by measurements of the interface pressure $p_{i}$ and is therefore not affected by sleeve material, friction, force equilibrium and details of the pressure field in water.

At a speed of $50 \mathrm{~m} / \mathrm{s}$ (Test II), Model 3 is substantially more accurate than models 1 and 2, indicating that the inertia of specimen and rubber sleeve have a greater effect in this regime, while frictional effects continue to be negligible. The accuracy of Model 4 is not affected by this increase in impact speed. The stress/strain curves produced with models 1, 2 and 3 become noisier at strains exceeding $3 \%$, due to increased radial velocity of the specimen and the consequent fluid-structure interaction.

\section{Effects of Pulse Shapers}

The effects of the presence of pulse shapers of different thickness are shown in Fig. 6 for Test I, at impact speed of $8 \mathrm{~m} / \mathrm{s}$. The stress/strain curves in Fig. 6 a are obtained using Model 1. In absence of pulse shapers, or with a pulse shaper of thickness $1 \mathrm{~mm}$, the initial portion of the measured stress/strain curves deviates substantially from the reference response, indicating a non-uniform pressure field in the water, whereas beneficial effects of the pulse shapers are obvious at thicknesses of 2 and $4 \mathrm{~mm}$ and they are greater for larger pulse shaper thickness. The cost of these beneficial effects on the stress/strain curves is illustrated in Fig. $6 \mathrm{~b}$ in terms of strain rate histories. The presence of a pulse shaper greatly reduces the maximum strain rate in the test, with greater reductions observed for larger thicknesses; the presence of pulse shaper however also makes the strain
Fig. 5 Accuracy of different analytical models at impact speed (a) $8 \mathrm{~m} / \mathrm{s}$; (b) $50 \mathrm{~m} / \mathrm{s}$ (a)

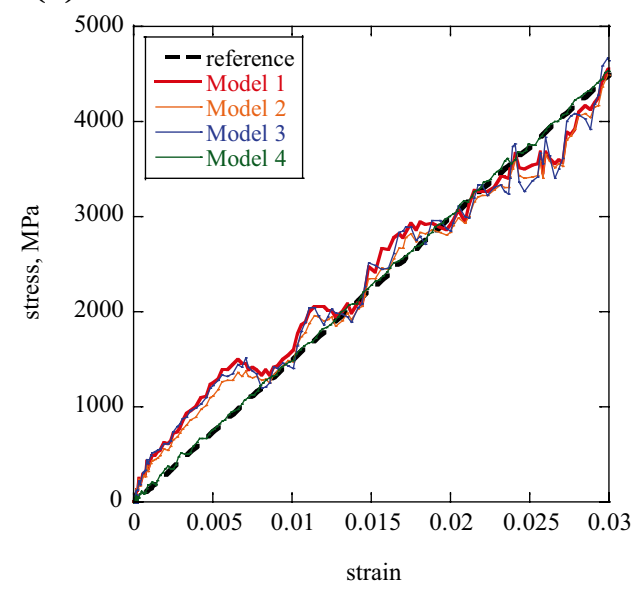

(b)

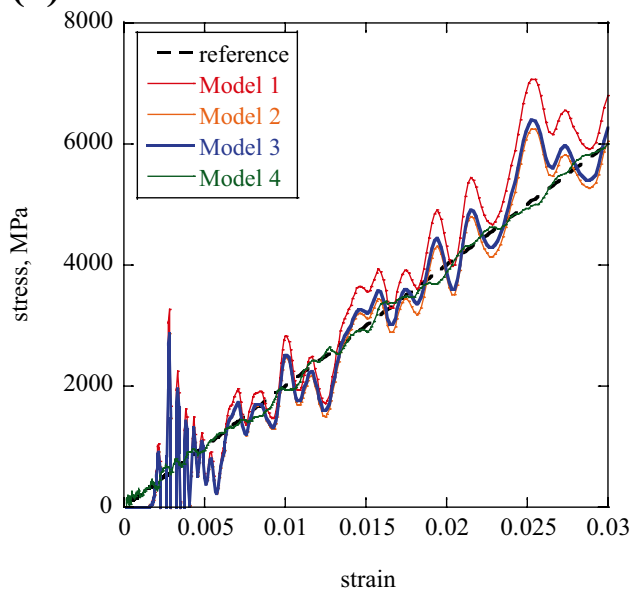


Fig. 6 Simulation of Test I for the case of an impact speed of $8 \mathrm{~m} / \mathrm{s}$. (a) Stress versus strain curves constructed using Model 1; (b) strain rate versus strain curves (a)

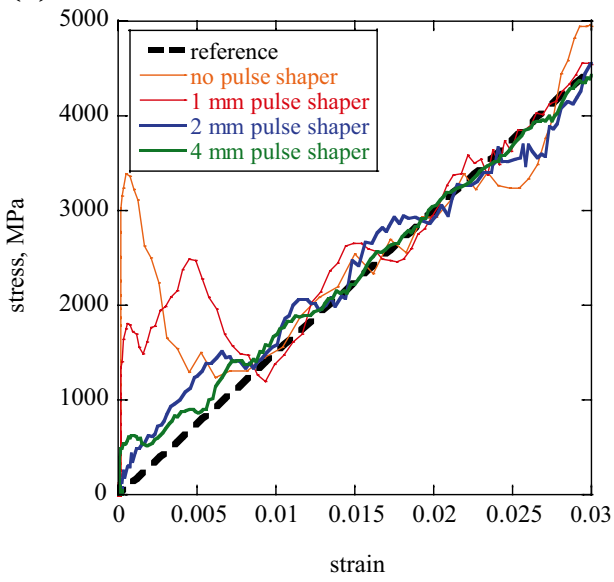

(b)

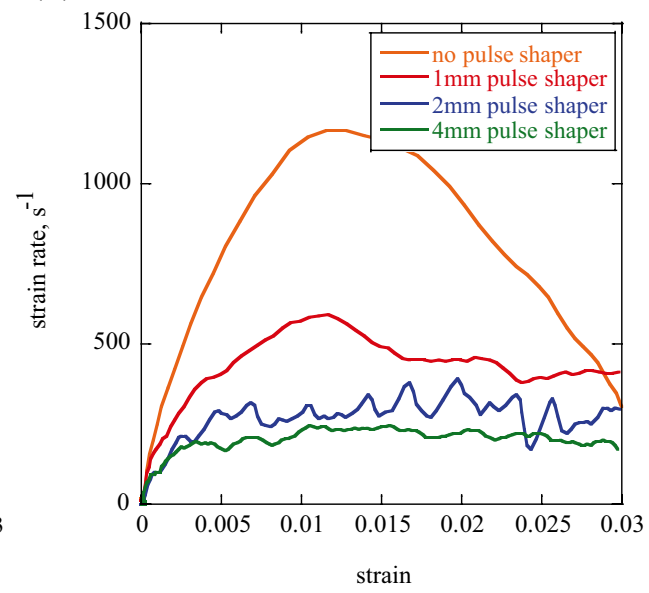

rate more constant in the test, which is a desirable feature. Qualitatively similar observations can be made at higher impact speeds and in the case of Test II. These findings are in line with those of previous studies on SHPB techniques [26-28]. In this study the investigation on pulse shapers is limited to a single rubbery material and a single cylindrical geometry. We envisage that using soft, plastically compressible materials (e.g. foams), tapered geometry, different sizes and multiple materials, would allow a finer adjustment of the incoming pulse and of the imposed strain rate histories; this is however not pursued further in this study.

\section{Comparison of Experiments and Simulations}

To validate the simulation techniques and modelling choices made in this paper, here we compare the results of an experiment presented in [16] (Test I on a composite fibre yarn, impact speed of $8 \mathrm{~m} / \mathrm{s}$ ) with our FE predictions. In Fig. 7a we present measurements and predictions of the force histories at the ends of the input and output bars in contact with the water, obtained from readings of strains at mid-span of the bars and using the established one-dimensional stress wave theory. We note that in this particular simulations we use a SHPB geometry as described in [16] and slightly different from that shown in Fig. 1, in that the bars used in this experiment had different cross-section, and the specimen also had different cross-section from that assumed in the rest of this paper (details are found in [16]).

The predicted and measured sets were found in broad agreement; their most apparent difference was the steeper rise of the force in the input bar predicted by the FE simulations compared to the measured one. This is likely due to the presence of more sources of damping in the experiments, compared to those modelled in the simulations. Such steep predicted rise of the force also results in a predicted initial strain rate higher than the measured one, visible in Fig. 7c and d. Figure 7a shows that force equilibrium is predicted to be achieved at approximately $75 \mu \mathrm{s}$ but is attained slightly later in the experiment; this is consistent with what is shown in the pressure fields of Fig. 4a. As expected, once equilibrium is achieved, the strain rate becomes approximately constant and the predictions and measurements of stress strain curves and strain rate versus strain curves are in agreement (we note that, as the force in the output bar is less noisy than that in the input bar, this one is used to construct stress/strain curves, as it is normal practice in SHPB experiments.). We conclude that the FE simulations presented in this paper are effective in this regime, and we will assume that their fidelity is not lost at higher impact speeds, as there is no particular reason to believe so. We also note that the predicted stress versus strain curve tend to be more noisy of the corresponding measured ones. This is again due to the presence of more damping sources in the tests compared to the predictions; it follows that one should generally expect, in the tests, better data than those predicted by the FE simulations, which is good news in terms of the development of the proposed technique.

\section{Towards Measurements at Ultra-high Strain Rates}

In this section we present predictions of the stress versus strain and of the strain rate versus strain curves for tests conducted using a rubber pulse shaper of thickness $4 \mathrm{~mm}$, at impact speeds of $20 \mathrm{~m} / \mathrm{s}$ (Test I), 50, 100 and $150 \mathrm{~m} / \mathrm{s}$ (Test II).

First, we note that the maximum stress expected in the test apparatus is at the interface between projectile and input bar (for Test I) or between projectile and input piston (Test II) and this is of magnitude $\rho c V / 2$, with $\rho, V$ being the density, speed of sound and impact velocity, respectively (note that projectiles and input bar/piston are all made from Ti64 in this study). This stress is expected to exceed the yield strength of the Ti64 components $\left(\sigma_{Y}=1 \mathrm{GPa}\right)$ only 
(a)

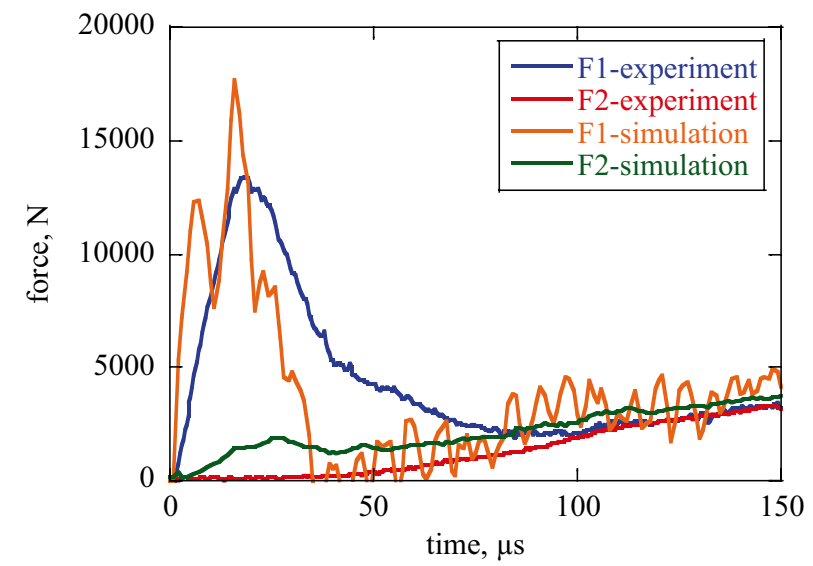

(c)

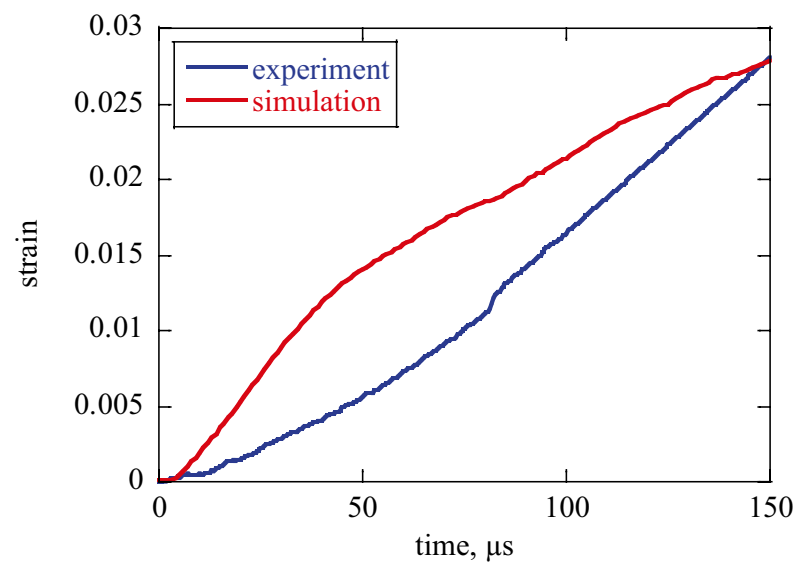

Fig. 7 Comparison of experiments and simulations of Test I, for the case of a Type I test on a composite fibre yarn, at an impact speed of $8 \mathrm{~m} / \mathrm{s}$. (a) Measured and predicted forces at the ends of the input and output bars in contact with water. (b) Measured and predicted stress/ strain curves. (c) Measured and predicted strain histories. (d) Meas- (b)

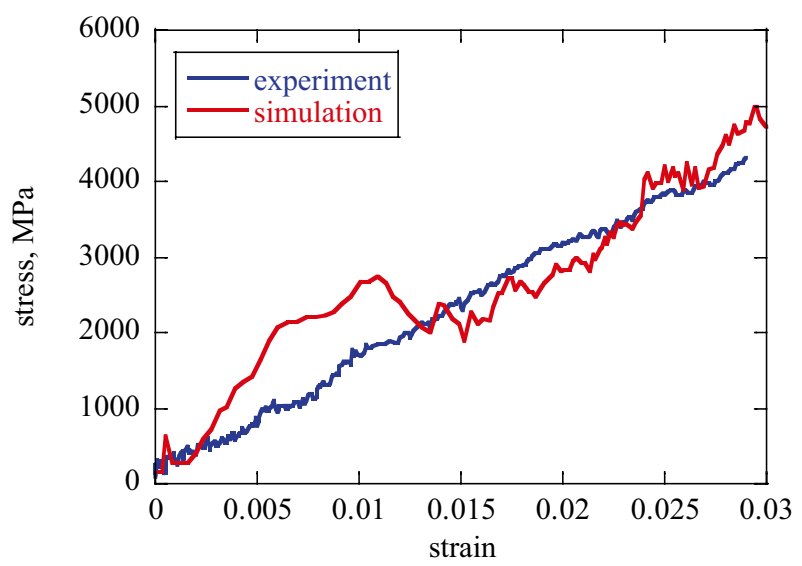

(d)

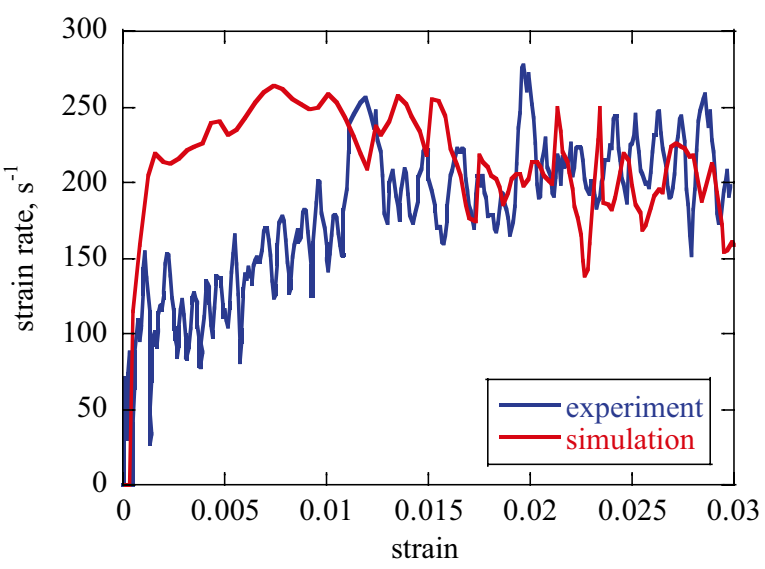

ured and predicted strain rate histories. Note that simulations of this tests were conducted using the an apparatus geometry as in [16]; this was slightly different from that presented in Fig. 1 as it had input and output bars of different diameter
Fig. 8 Simulations of Test I, for the case of an impact speed of $20 \mathrm{~m} / \mathrm{s}$ with a pulse shaper of thickness $4 \mathrm{~mm}$. (a) Actual and predicted stress/strain curves using models 3 and 4. (b) Predicted strain rate history (a)

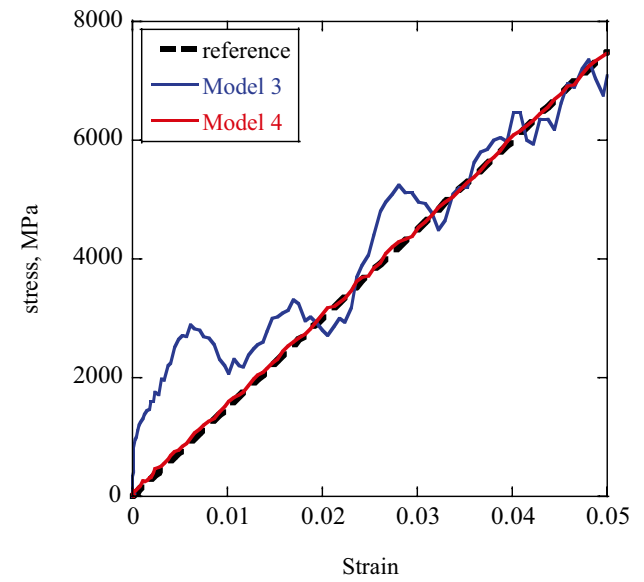

(b)

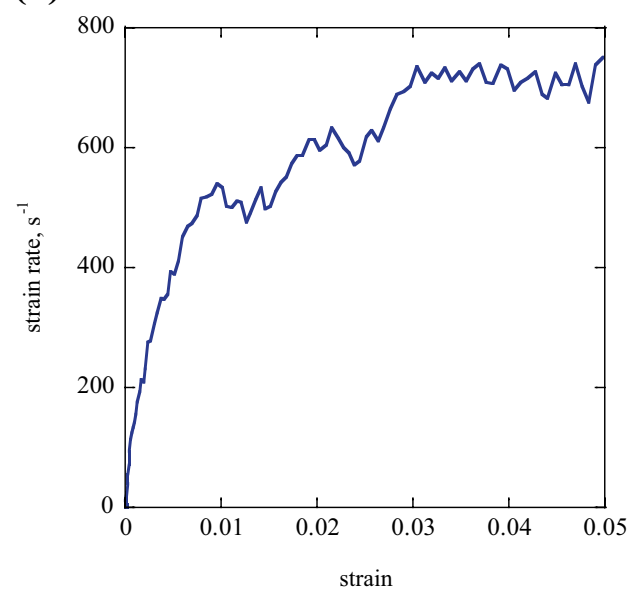


Fig. 9 Simulations of Test II, for the case of an impact speed of $50 \mathrm{~m} / \mathrm{s}$ with a pulse shaper of thickness $4 \mathrm{~mm}$. (a) Actual and predicted stress/strain curves using models 3 and 4 . (c) Predicted strain rate history (average of $1580 / \mathrm{s}$ ) (a)

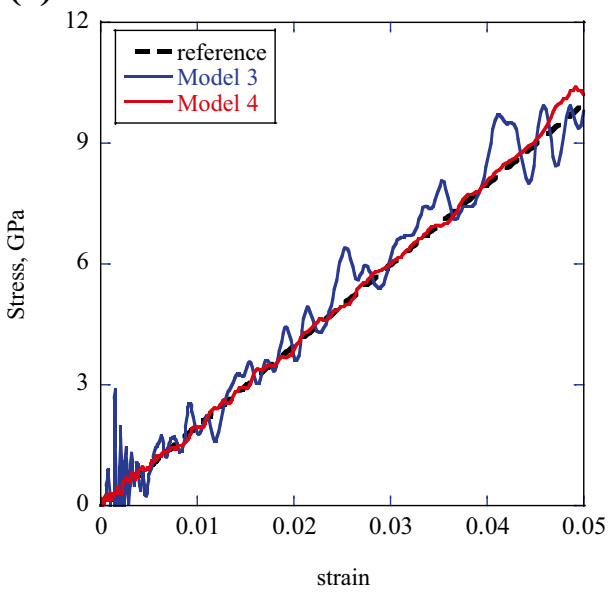

(b)

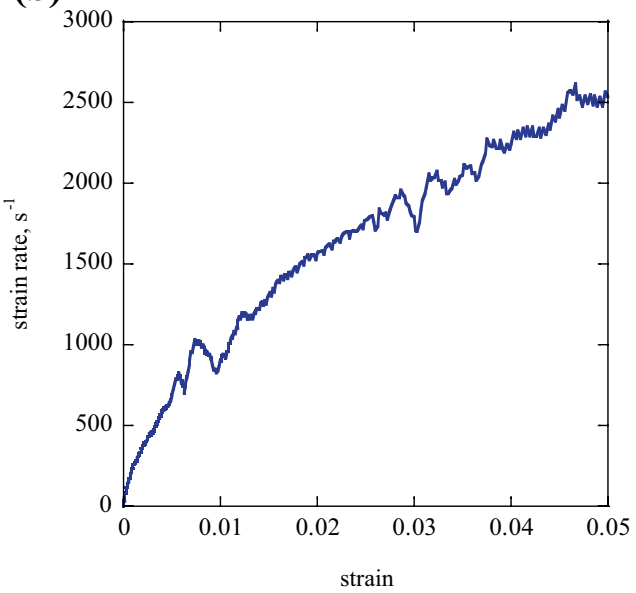

at impact speeds of $100 \mathrm{~m} / \mathrm{s}$ and above. Our simulations confirm this; limited plasticity is detected at the impact end of the apparatus only in the simulations at 100 and $150 \mathrm{~m} / \mathrm{s}$. The emergence of plastic behavior renders the projectile and input piston disposable, which is only a practical problem. It also affects the shape of the loading pulse sent in the water, slightly decreasing the peak stress and increasing the pulse time duration, compared to the case of an elastic response; this effect is qualitatively similar to the effect of any pulse shaper. Overall, the yielding of the metallic components does not compromise the test, but reduces slightly the maximum achievable strain rate.

At $20 \mathrm{~m} / \mathrm{s}$ (Fig. 8), which is the practical limit for most SHPB systems, the FE simulations predict that force equilibrium can be achieved and a valid stress/strain curve can be measured by either wave analysis of the strains in the input/output bars or, much more accurately, from measurements of the interface pressure $p_{i}$. The curve predicted via Model 3 (wave analysis) is much more noisier compared to that predicted by Model 4 (interface pressure); we note again that no source of damping (apart from metal plasticity and the viscosity of the water) has been modelled in the FE simulations; in addition, the input and output bars in the FE simulations are free and can be affected by flexural waves, while these would be suppressed by the regularly spaced supports implemented in reality, which act as dampers. The strain rate is approximately constant after a brief transient at strains exceeding $2.5 \%$, and approximately equal to $700 / \mathrm{s}$ when this thick pulse shaper is used.

The results at $50 \mathrm{~m} / \mathrm{s}$ (Test II, Fig. 9) are similar to those in Fig. 8. The noise in the stress/strain curves when using Model 3 increases compared to the case of $20 \mathrm{~m} / \mathrm{s}$ (note the different vertical scales in Figs. 8 and 9), whereas it remains very low when relying on the interface pressure (Model 4). Strain rates are much higher and reach $2500 / \mathrm{s}$ at a strain of $5 \%$, however they steadily increase with time and applied strain; this is not a desirable feature, which could be corrected by a better design of the pulse shaper.
Fig. 10 Simulations of Test II, for the case of an impact speed of $100 \mathrm{~m} / \mathrm{s}$ with a pulse shaper of thickness $4 \mathrm{~mm}$. (a) Actual and predicted stress/strain curves using models 3 and 4 . (c) Predicted strain rate history (average of $2650 / \mathrm{s}$ ) (a)

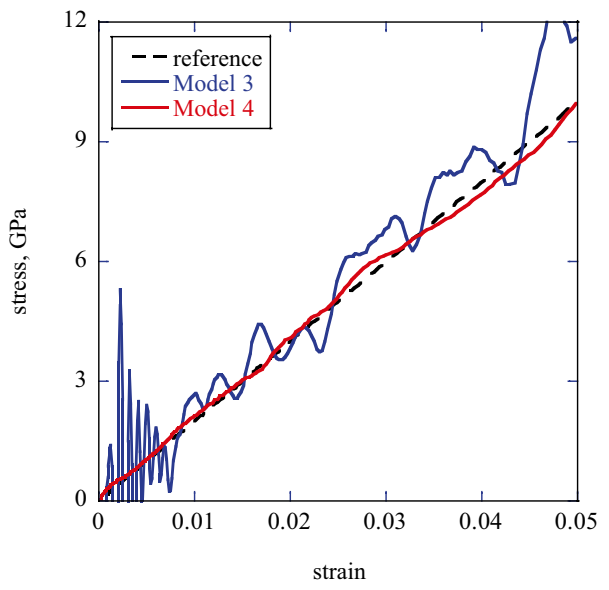

(b)

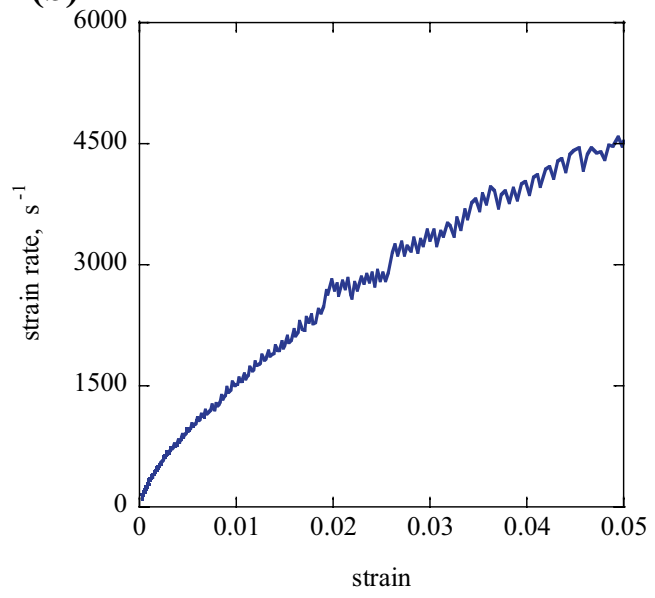


Fig. 11 Simulations of Test II, for the case of an impact speed of $150 \mathrm{~m} / \mathrm{s}$ with a pulse shaper of thickness $4 \mathrm{~mm}$. (a) Actual and predicted stress/strain curves using models 3 and 4 . (c) Predicted strain rate history (average of $4090 / \mathrm{s}$ ) (a)

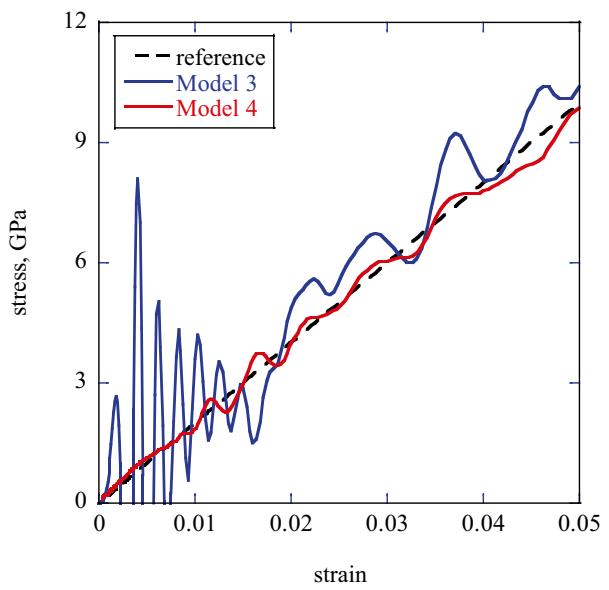

(b)

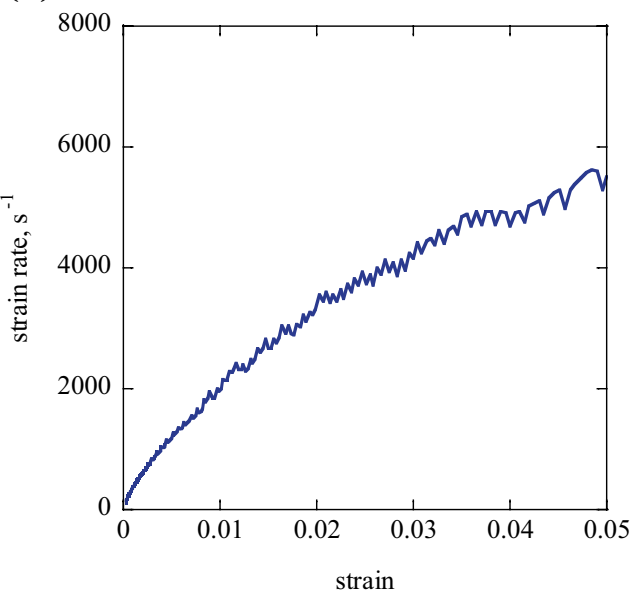

As the impact speed increases to $100 \mathrm{~m} / \mathrm{s}$ (Test II, Fig. 10), the noise in the stress versus strain curve obtained by Model 3 increases further, while those obtained via Model 4 are still very accurate; the maximum strain rate reaches $4500 / \mathrm{s}$. These trends are seen to continue as the impact speed increases to $150 \mathrm{~m} / \mathrm{s}$ (Test II, Fig. 11), corresponding to a maximum strain rate of $5500 / \mathrm{s}$. At this speed, the noise in stress/strain curves produced using Model 3 exceeds $2 \mathrm{GPa}$, which renders these curves practically unusable even for ductile materials. Curves produced from reading of the interface pressure via Model 4 start showing some noise, however they still capture effectively a valid stress/ strain response even at very small strains.

In summary, Test $\mathrm{I}$ is adequate for tensile testing of solid materials at high strain rates (100-1000/s). Stress/strain curves produced by analysis of the stress waves in the SHPB are accurate for ductile materials (of ductility higher than $3 \%$ ) in this strain rate range, and for more brittle solids at strain rates up to approximately $500 / \mathrm{s}$. For brittle materials in the strain rate range 500-1000/s, measurements of the interface pressure are needed to obtain accurate data.

With regards to Test II, if stress/strain curves are obtained from measurements of the pressure $p_{0}$ in the water, these are adequate for all ductile materials up to strain rates of order 2000 /s. For brittle materials (at any strain rate) and for ductile materials at strain rates above approximately $2000 / \mathrm{s}$, measurements of the interface pressure $p_{i}$ is required. The effectiveness of Test II when relying on measurements of $p_{i}$ has been ascertained here up to strain rates of order $5000 / \mathrm{s}$ for elastic materials. Additional experimental problems may arise when the strain rates are pushed to even higher values: for example, the occurrence of bulk cavitation at the water/sleeve interface, and the consequent ceasing of the load and the possible detachment of the specimen from the rubber sleeve. Assessment of these potential problems would require more sophisticated computational techniques (e.g. employing coupled eulerian-lagrangian simulations and/or adaptive remeshing) and is left as a topic for future studies.

\section{Conclusions}

In this study we assessed by FE simulations the detailed performance of two test techniques aimed at measuring tensile stress versus strain curves for solid materials at high and ultra-high strain rates. We developed four simple analytical models to extract the stress versus strain curves from the tests data, and ranked their effectiveness in different cases by comparing to the FE simulations. The main conclusions are as follows:

- Test I, presented in [16], is an adequate and simple technique to conduct measurements at strain rates up to $1000 / \mathrm{s}$.

- For brittle materials (ductility lower than 3\%), in Test I the stress history can be measured by signals in the input and output bar of a SHPB for strain rates up to $500 / \mathrm{s}$; at higher strain rates, direct measurement of the pressure applied on the ring specimens is recommended.

- Test II is adequate to measure tensile stress versus strain curves at strain rates exceeding $1000 / \mathrm{s}$.

- For strain rates up to $2000 / \mathrm{s}$ on ductile materials, in Test II the stress history can be determined by readings of the pressure at any point in the fluid.

- For brittle materials (at any strain rates) and for ductile materials at rates greater than 2000 /s, in Test II we recommend direct measurements of the pressure applied on the ring specimens.

- Unlike all existing test techniques, both Test I and Test II are not affected by gripping problems and can measure the sensitivity of elastic properties to the applied strain rate, provided that the pressure applied on the ring specimens is directly measured. 


\section{Declarations}

Ethics Statement The authors declare that the content of this paper has no ethical implications.

Conflict of Interests Both authors declare no conflict of interests or competing interests.

Open Access This article is licensed under a Creative Commons Attribution 4.0 International License, which permits use, sharing, adaptation, distribution and reproduction in any medium or format, as long as you give appropriate credit to the original author(s) and the source, provide a link to the Creative Commons licence, and indicate if changes were made. The images or other third party material in this article are included in the article's Creative Commons licence, unless indicated otherwise in a credit line to the material. If material is not included in the article's Creative Commons licence and your intended use is not permitted by statutory regulation or exceeds the permitted use, you will need to obtain permission directly from the copyright holder. To view a copy of this licence, visit http://creativecommons.org/licenses/by/4.0/.

\section{References}

1. Kuhn H, Medlin D (2000) High Strain Rate Tension and Compression Tests, in ASM Book Vol 8, Mechanical testing and evaluation, ASM international

2. Hopkinson J (1872) On the rupture of iron wire by a blow. Proc Literary and Philosophical Society of Manchester 1:40-45; 119-121

3. Hopkinson B (1904) The effects of momentary stresses in metals. Proceedings of the Royal Society of London

4. Hopkinson B (1914) X. A method of measuring the pressure produced in the detonation of high, explosives or by the impact of bullets. Philosophical Transactions of the Royal Society of London. Series A, Containing Papers of a Mathematical or Physical Character 213(497-508):437-456

5. Kolsky H (1949) An investigation of the mechanical properties of materials at very high rates of loading. Proceedings of the physical society. Section B 62(11):676

6. Davies EDH, Hunter SC (1963) The dynamic compression testing of solids by the method of the split Hopkinson pressure bar. J Mech Phys Solids 11(3):155-179

7. Tagarielli VL, Deshpande VS, Fleck NA (2008) The high strain rate response of PVC foams and end-grain balsa wood. Compos B Eng 39(1):83-91

8. Pellegrino A, Tagarielli VL, Gerlach R, Petrinic N (2015) The mechanical response of a syntactic polyurethane foam at low and high rates of strain. International Journal of Impact Engineering 2015;75214-221

9. Hoggatt CR, Recht RF (1969) Stress-strain data obtained at high rates using an expanding ring. Exp Mech 9(10):441-448

10. Warnes RH, Karpp RR, Follansbee PS (1986) The freely expanding ring test-a test to determine material strength at high strain rates. Transactions of the ASME. J Eng Mater Technol 1986;108(4):335-9
11. Al-Maliky N, Parry DJ (1994) Measurements of high strain rate properties of polymers using an expanding ring method. Journal De Physique IV:JP 4(8): C8-71-C8-76

12. Zhang H, Ravi-Chandar K (2013) On the dynamics of necking and fragmentation - I. Real-time and post-mortem observations in $\mathrm{Al}$ 6061-O. Int J Fract 142(3-4):183-217

13. Zhang H, Ravi-Chandar K (2008) On the dynamics of necking and fragmentation - II. Effect of material properties, geometrical constraints and absolute size. Int J Fract 150(1-2): 3-36

14. Zhang H, Liechti K, Ravi-Chandar K (2009) On the dynamics of localization and fragmentation. III. Effect of cladding with a polymer. Int J Fract 155(2):101-18

15. Zhang H, Ravi-Chandar K (2010) On the dynamics of localization and fragmentation-IV. Expansion of Al 6061-O tubes. Int J Fract 163(1-2):41-65

16. Zhou J, Pellegrino A, Heisserer U, Duke PW, Curtis PT, Morton J, Petrinic N, Tagarielli VL (2019) A new technique for tensile testing of engineering materials and composites at high strain rates. Proceedings of the Royal Society A 475(2229):20190310

17. Zhou J, Tagarielli VL, Heisserer U, Curtis PT (2018) An Apparatus for Tensile Testing of Engineering Materials. Exp Mech 58(6):941-950

18. Zhou J, Tagarielli V, Heisserer U, Curtis P, Duke PW (2021) The sensitivity of the tensile properties of PMMA, Kevlar ${ }^{\circledR}$ and Dyneema ${ }^{\circledR}$ to temperature and strain rate. Polymer 225(26): 123781

19. Roth FL, Driscoll RL, Holt WL (1942) Frictional properties of rubber. United States Bureau of Standards -- J Res 1942;28(4): 439-462

20. Arezoo S, Tagarielli VL, Siviour CR, Petrinic N (2013) Compressive deformation of Rohacell foams: Effects of strain rate and temperature. Int J Impact Eng 51:50-57

21. Siegkas P, Tagarielli VL, Petrinic N, Lefebvre LP (2011) The compressive response of a titanium foam at low and high strain rates. J Mater Sci 46(8):2741-2747

22. ANSYS GRANTA CES Edupack 2017

23. Schiffer A, Tagarielli VL, Petrinic N, Cocks AC (2012) The response of rigid plates to deep water blast: analytical models and finite element predictions. J Eng Mater Technol 79(6):061014

24. Schiffer A, Tagarielli VL (2012) The response of rigid plates to blast in deep water: fluid-structure interaction experiments. Proceedings of the Royal Society A: Mathematical, Physical and Engineering Sciences 468(2145):2807-2828

25. Schiffer A, Tagarielli VL (2017) Underwater blast loading of water-backed sandwich plates with elastic cores: Theoretical modelling and simulations. Int J Impact Eng 102:62-73

26. Lu YB, Li QM (2010) Appraisal of pulse-shaping technique in split Hopkinson pressure bar tests for brittle materials. International Journal of Protective Structures 1(3):363-390

27. Chen X, Ge L, Zhou J, Wu S (2015) Experimental study on split Hopkinson pressure bar pulse-shaping techniques for concrete. J Mater Civ Eng 28(5):04015196

28. Frew DJ, Forrestal MJ, Chen W (2002) Pulse shaping techniques for testing brittle materials with a split Hopkinson pressure bar. Exp Mech 42(1):93-106

Publisher's Note Springer Nature remains neutral with regard to jurisdictional claims in published maps and institutional affiliations. 